\title{
LAUDO PERICIAL EM LOCAIS ATINGIDOS POR INCÊNDIOS FLORESTAIS
}

\author{
Alexandre Figueiredo de Lemos $^{1}$
}

\begin{abstract}
RESUMO
O Corpo de Bombeiros Militar tem como uma de suas atribuições a realização de perícias de incêndio e conseqüentemente, é solicitado para realizar inúmeros exames periciais para determinação das causas e origens dos incêndios florestais.Diante disso, o CBM/MS, através da portaria do Comandante Geral, elabora e emite os laudos periciais confeccionados por seus oficiais especializados em perícia de incêndio aos órgãos solicitantes.Contudo o CBM/MS carece de uma padronização dos laudos periciais específicos para incêndios florestais, tendo em vista a necessidade que, além de analisar pontos fundamentais para sua confecção, temos que entender que este laudo está inserido no conceito de perícia ambiental.

Não é mais possível deixar de atrelar ao laudo pericial os danos ambientais causados pelo incêndio.Diante do exposto é que surgiu a idéia deste trabalho, que é apresentar para o Corpo de Bombeiros do MS uma proposta de padronização na elaboração dos laudos periciais para áreas atingidas por incêndios florestais.

Palavras-chave: Perícia, Incêndio Florestal, Laudos
\end{abstract}

\section{INVESTIGATION REPORT ON WILDFIRE INCIDENT}

\begin{abstract}
The Military Body of Firemen has as one of its attributions the accomplishment of fire investigation, it is requested to determine the causes of wildfires. Ahead of this, the CBM/MS elaborates and emits the investigation report to the solicitant agencies. However the CBM/MS needs a pattern to wildfire investigation reports. It is not possible to leave the environment damages out of the report. That's where the idea to this work came from. It's a proposal of pattern to wildfire investigation report.
\end{abstract}

\section{INTRODUÇÃO}

O Corpo de Bombeiros Militar do Estado de Mato Grosso do Sul, órgão integrante da Secretaria de Justiça e Segurança Pública, possui dentre suas atribuições constitucionais e conforme Lei $n^{\circ}$ 049/90 (Lei de Organização Básica), a realização da perícia de incêndios através de seus oficiais, possuidores do curso de especialização em Perícias de Incêndios e Explosões.

Dentre os tipos de perícias de incêndios, a de incêndio florestal tem tido um maior destaque, o que faz sentido, se analisarmos que a economia do Estado está baseada na agricultura e pecuária e concomitantemente, enfrentamos anualmente o período da estiagem, o que faz um somatório muito favorável a queimadas e conseqüentemente aos incêndios florestais.Diante da demanda de solicitações de perícias para as causas e origens dos incêndios florestais para o CBM/MS e ainda, ciente que o resultado do exame pericial irá auxiliar o magistrado na aplicação da lei nos delitos contra o meio ambiente. Urge a necessidade do Corpo de Bombeiros Militar do Estado de Mato Grosso do Sul, padronizar seus laudos periciais especificamente para os incêndios florestais, de forma a torná-los mais eficaz e com informações técnicas e científicas de qualidade, para que possamos além de elucidar tecnicamente as causas e origens dos incêndios florestais, que se possa também informar ao magistrado os danos causados ao meio

\footnotetext{
1.

Capitão QOBM do Corpo de Bombeiros Militar do Estado de Mato Grosso do Sul

Especialista em Perícia Ambiental-Área de Concentração em Perícias em Crimes Contra o Meio Ambiente

Especialista em Perícia de Incêndio e Explosões

Especialista em Gestão em Segurança Pública

Corpo de Bombeiros Militar do Estado de Mato Grosso do Sul
} 
ambiente em conseqüência do incêndio florestal que em sua grande maioria, tem início nas queimadas não autorizadas pelos órgãos ambientais competentes.

\section{Diferenças entre laudo pericial e laudo técnico}

Apesar de terem a mesma finalidade e destinação, a diferença básica entre Laudo Pericial e Laudo Técnico, é a competência legal para sua realização, ou seja, apesar de serem ambas vistorias técnicas realizadas por pessoas habilitadas para sua desenvoltura, a competência legal para sua realização é que determina a diferença entre elas.

O Laudo Pericial diverge na sua aplicabilidade, pois o responsável pela sua realização é pessoa uma designada por força de lei (peritos oficiais), ou nomeadas pelo judiciário para atuar em determinado feito (perito nomeado).

Já o laudo técnico é um documento resultante de uma vistoria realizada por uma pessoa que apesar de ter conhecimento técnico no assunto, não tem a competência legal para atuar como perito (oficial ou nomeado).

\section{Perícias de incêndios florestais}

$\mathrm{O}$ exame pericial em locais atingidos por incêndios florestais por estar inserido no conceito da perícia ambiental, possui algumas características básicas e uma delas é a grande extensão de área queimada, o que dificulta de sobremaneira a identificação do foco inicial, ou seja a área pontual específica no terreno onde iniciou o incêndio.

Outra dificuldade básica muito comum em ocorrências desta natureza é a preservação do local através do isolamento da área, devido a grande extensão a ser preservada.

Não podemos ainda deixar de incluir uma variável muito importante que é a questão do tempo. A perícia em áreas atingidas por incêndios florestais devem ser realizadas logo após a extinção do incêndio, pois caso contrário, corre-se o risco da destruição dos padrões de carbonização importantes deixados no terreno.

Portanto, quando $\mathrm{o}$ perito não conseguir identificar o foco inicial do incêndio, o mesmo tem que se ater a identificar a zona de origem do incêndio, pois através desta informação é que será possível identificar de que fazenda, unidade de conservação, parque e etc., teve início o incêndio e, desta forma delimitar melhor o universo dos responsáveis.

Com base nestas informações e nas demais que constam no corpo do laudo pericial, como por exemplo, se havia preocupação do responsável na prevenção da área, e em consonância com os conceitos do direito difuso, a autoridade competente poderá responsabilizar o proprietário do local, pelo mesmo não ter tomado o devido cuidado com sua área, contribuindo de forma involuntária para a ocorrência do incêndio florestal.

\section{METODOLOGIA}

A metodologia utilizada foi a revisão bibliográfica e descritiva, onde inicialmente foi feito contato com os Corpos de Bombeiro do Brasil, via telefone e internet, em busca de informações a respeito da existência de laudos periciais específicos para incêndios florestais.

Em nenhum Corpo de Bombeiro do Brasil, possui um laudo específico para incêndios florestais, o que existe, são seções de perícias ativadas que executam as atividades de perícia, mas sem uma padronização formal específica para incêndios florestais.

Realizadas as consultas nos Corpos de Bombeiros, passamos para a pesquisa das leis afins aos incêndios florestais.

$\mathrm{Na}$ fase seguinte, foi realizada a análise dos diversos tipos de laudos de Incêndio Florestal emitidos pelo Corpo de Bombeiros do MS, cujo enfoque principal era a parte totalmente técnica do surgimento do fogo e laudos específicos de perícia ambiental, onde o enfoque principal eram os danos causados ao meio ambiente.

Convicto de que os Laudos Periciais em áreas atingidas por incêndios florestais emitidos pelo Corpo de Bombeiros não poderão estar separados dos danos ambientais, é que apresentamos este trabalho.

\section{RESULTADOS E DISCUSSÃO}

O roteiro para a realização da perícia em locais atingidos por incêndios florestais deverá ser utilizada pelos peritos, de forma a nortear suas atividades em campo, não quer dizer que em todas as situações deverão conter os itens abaixo relacionados. 
O importante é que os peritos no desenvolvimento de suas funções, estejam sempre atentos para os itens relacionados com os danos ambientais em estudo no momento e ter a consciência que a perícia ambiental é multidisciplinar e caso haja possibilidade e necessidade, saber onde solicitar apoio de especialistas para cada caso.

Portanto o roteiro descrito a seguir está dividido em quatro princípios básicos que são: 1-Exame Detalhado do Local, 2- Diagnóstico Ambiental da Área, 3- Impactos Ambientais ocasionados pelo incêndio e 4- Análise específica da propagação do incêndio, culminando na conclusão do laudo, apresentando as causas e as origens do incêndio florestal.

\section{1- Exame Detalhado do Local .}

- Localização da Área

- Situação Legal da Área

- Perfil Climatológico da Região

- Recursos Hídricos da Região

- Topografia

- Especificação da Vegetação e Flora

- Especificação da Fauna

- Área de Interesse Histórico ou Cultural

- Área de Preservação Ambiental

\section{2- Diagnóstico Ambiental da Área}

- Uso atual da terra.

- Avaliação da Situação Ecológica Atual

3-Impactos Ambientais ocasionados pelo Incêndio

\section{4- Estudo das causas e origens do Incêndio Florestal}

- Coleta de Depoimento das testemunhas

- Idoneidade do Local

- Descrição da Zona de Origem

- Formas de Propagação e Fenômenos do Incêndio

- Descrição do Foco Inicial

- Forma do Surgimento do Incêndio

- Extinção do Incêndio e Atuação do Socorro

- Sistema Preventivo do Local

- Seguro Contra Incêndio

- Correlação dos Elementos Obtidos
- Conclusão

- Anexos

\section{CONCLUSÕES E RECOMENDAÇÕES}

Devido a grande importância e relevância de temas e ações relacionadas ao meio ambiente, o CBM/MS através de uma nova reestruturação em seu organograma, criou a Diretoria de Proteção Ambiental do $\mathrm{CBM} / \mathrm{MS}$, com a finalidade de atuar em ocorrências envolvendo principalmente os Incêndios Florestais, Produtos Perigosos e Perícia Ambiental relacionada com estes temas.

Urge a necessidade do Corpo de Bombeiros Militar do Estado de Mato Grosso do Sul se preparar e padronizar um laudo específico para apurar as causas e origens de incêndios florestais, dando ênfase aos danos ambientais causados por este sinistro.

Entendendo que as ocorrências envolvendo especificamente os incêndios florestais, onde após o seu combate surge a necessidade iminente de apurar responsabilidades e danos causados e ainda, diante da máxima que a pesquisa só é realizada devido a necessidade de resolver algum problema, é que surgiu a idéia da realização, de uma padronização de laudo pericial em locais atingidos exclusivamente por Incêndios Florestais contemplando principalmente os danos ambientais e as necessidades jurídicas que um laudo pericial requer.

Diante desta necessidade, fizemos uma minuciosa pesquisa unindo o conhecimento técnico do surgimento e propagação dos incêndios que é um mister do Corpo de Bombeiros e as ciências jurídicas, de modo a concentrar em um só documento dados confiáveis para o laudo pericial seja utilizado para o fim a que se destina, que é dar o esclarecimento e subsídio ao magistrado na aplicação da Lei.

\section{REFERÊNCIAS}

Âmbito Jurídico $<$ www.ambito-juridico.com. br/aj/damb0003.html>,acessado em 15/09/03.

Âmbito Jurídico $<w w w$.ambito-juridico.com. br/aj/damb0002.html>,acessado em 15/09/03. 
BRASIL. Constituição (1988). Constituição da República Federativa do Brasil. Brasília, DF: Senado, 1988.

BRASIL. Código de Processo Penal. Organização dos textos, notas remissivas e índices por Juarez de Oliveira. 28. ed. São Paulo: Saraiva, 1989.

CONSTANTINO, Carlos Ernani. A Lei Ambiental Comentada. São Paulo: Ed. Atlas,2001.

CORPO DE BOMBEIROS MILITAR DO DISTRITO FEDERAL. Manual de Determinação de Causas dos Incêndios Florestais: Brasília, DF.

COUTO, Elmar Alfenas. Incêndios Florestais. Viçosa: UFV, 1995.

ESPÍNDULA, Alberi. Metodologia das Perícias Ambientais no Âmbito da Justiça Criminal e Cível: Brasília, DF.

FERREIRA, Aurélio Buarque de Holanda. Dicionário Eletrônico. Século XXI. São Paulo. MGB Informática Ltda, [1999]. 1 CD ROM. Windows 3.0.

\footnotetext{
INSTITUTO BRASILEIRO DO MEIO AMBIENTE E DOS RECURSOS NATURAIS RENOVÁVEIS. Lei Federal $n^{\circ}$ 9.605, de 12 de fevereiro de 1998. Dispõe sobre as sanções penais e administrativas derivadas de condutas e atividade lesivas ao meio ambiente e dá outras providências. Brasília, DF, 2000.
}

INSTITUTO BRASILEIRO DO MEIO AMBIENTE E DOS RECURSOS NATURAIS RENOVÁVEIS. Decreto Federal $\mathrm{n}^{\circ} 3.179$, de 21 de setembro de 1999. Dispõe sobre a especificação das sanções aplicáveis às condutas e atividades lesivas ao meio ambiente e dá outras providências. Brasília, DF, 2000.

INPE < www.inpe.gov.br $>$, acessado em 24/09/2003.

KUNZE, Eduardo - Prof.. Dr.Phil. Roteiro Geral para perícias em Meio Ambiente: Brasília, DF.

LUDWING, Artulino. A Perícia em Local de Crime. Canoas: Ed. Da ULBRA, 1996.

MATO GROSSO DO SUL. Constituição (1989). Constituição do Estado de Mato Grosso do Sul. Campo Grande: Assembléia Legislativa, 1989.

MINISTÉRIO DO MEIO AMBIENTE E DOS RECURSOS NATURAIS RENOVAVEIS. Investigação da Causa do Incêndio Florestal: Brasília, DF.

MINISTÉRIO DO MEIO AMBIENTE, DOS RECURSOS HÍDRICOS E DA AMAZÔNIA LEGAL. Manual de Operações de Prevenção e Combate aos Incêndios Florestais: Brasília, DF.

SZNICK, Valdir. Direito Penal Ambiental. São Paulo: Ed. Ícone, 2001. 